Working Paper 9415

\title{
BANKRUPTCY RULES AND DEBT CONTRACTING: ON THE RELATIVE EFFICIENCY OF ABSOLUTE PRIORITY, PROPORTIONATE PRIORITY, AND FIRST-COME, FIRST-SERVED RULES
}

by Stanley D. Longhofer

Stanley D. Longhofer is an economist at the Federal Reserve Bank of Cleveland. The author is grateful to Charles Kahn for his encouragement and advice, to Richard Arnott, Charles Calomiris, Stefan Krasa, Da-Hsiang Donald Lien, Robert McDonald, George Pennacchi, Anne Villamil, and Andrew Winton for useful comments and suggestions, and to Hai-Ling Huai for helpful research assistance. He would also like to thank participants at the 1992 Southeast Economic Theory and Trade Meetings and those attending workshops at the University of Illinois, Strathclyde University, the Federal Reserve Bank of Cleveland, the University of Kansas, and Northwestern University. Part of this research was supported by a fellowship from the Irwin Family Foundation.

Working Papers of the Federal Reserve Bank of Cleveland are preliminary materials circulated to stimulate discussion and critical comment. The views stated herein are those of the author and not necessarily those of the Federal Reserve Bank of Cleveland or of the Board of Governors of the Federal Reserve System. 


\begin{abstract}
Typical corporate finance folklore tells us that existing proportionate priority and absolute priority rules in bankruptcy have evolved in order to eliminate inefficiencies that result when lenders rush to retrieve their assets from a firm in financial distress. This paper shows that when a firm is faced with a moral hazard problem, first-come, first served rules reduce lenders' incentives to free ride on the monitoring efforts of each other. As a result, these rules may reduce the total social cost of loan contracts compared to other bankruptcy rules. The bankruptcy rules described here mimic important contractual arrangements found in real-world debt contracts.
\end{abstract}


Standard arguments in corporate finance tell us that existing bankruptcy rules have evolved to eliminate inefficiencies that result when lenders rush to retrieve their assets from a firm under financial distress. Thus, both Chapter 7 and Chapter 11 bankruptcy proceedings ostensibly maintain absolute priority among creditor groups and provide for assets to be divided proportionately among creditors of equal priority. This rationale, however, may not always be valid. Moral hazard problems relating to the choice of project may make the act of "running" on a firm desirable, since it can help align investment incentives.

This paper looks at the problem of an entrepreneur who must raise outside funds to finance one of two investment altematives. One of these projects is risky, so that any interest rate which ensures lenders their reservation return causes the entrepreneur to earn negative profits. Nevertheless, the firm is unable to commit to the less risky project, so neither can be undertaken.

First-come, first-served (FCFS) rules, often considered a benchmark in the absence of other bankruptcy rules, serve to diminish this moral hazard problem. We derive a mixed-strategy equilibrium in which lenders monitor the firm with some positive probability. When the firm is caught investing in the risky project, it is liquidated; otherwise, it is allowed to continue. Although an equilibrium may exist under both FCFS rules and proportionate priority rules (PPRs), we demonstrate that it is less likely to exist under PPRs, and that when it does, the FCFS equilibrium is Pareto superior. Furthermore, FCFS rules continue to dominate even when lenders are able to appoint a delegated monitor and provide that monitor with absolute seniority (absolute priority rules, or APRs).

The fact that lenders can run on the firm when they observe that it has chosen the risky project helps keep the firm honest. The FCFS aspect of asset distribution keeps lenders from wanting to free ride on the monitoring efforts of others - those lenders who monitor are first in line to receive their claim on the firm's assets and are thus likely to be paid in full. Lenders who wait to observe the monitoring of others are less likely to receive anything if the firm goes under. This process is much like that 
described in the banking papers of Calomiris and Kahn (1991) and Calomiris, Kahn, and Krasa (1991), where demandable debt is used to control the banker's moral hazard problem, while sequential service prevents depositors from free riding on the monitoring efforts of others.

The bankruptcy rules we describe mimic many important contractual arrangements found in realworld debt contracts. A trade creditor might refuse to ship new supplies to a firm when its prospects look bad, effectively refusing to renew its loan. Alternatively, a factoring company might decide to no longer guarantee payments for new accounts receivable generated with that firm. Also, a bank has the right to seize a borrower's assets under the bank's control when it discovers that the borrower is in default. In each case, the action taken by one creditor sends a signal to the rest of the market as to the creditworthiness of the borrower, thereby forcing a poor borrower into bankruptcy. As such, the act of monitoring acquires a public-good aspect. Like all public goods, too little monitoring will occur unless the provider can capture and exclude others from its benefits. FCFS rules, and other contracts containing their features, serve to compensate monitors for their actions.

Chapter 11 bankruptcy proceedings are often criticized by both legal and economic scholars for the violation of absolute priority that often results. ${ }^{1}$ Our findings suggest that such violations may in fact increase social welfare. By refusing to reward senior lenders who fail to monitor the debtor, Chapter 11 strengthens the monitoring incentive: Lenders who wish to obtain the full value of their claims in default must obtain their assets before a bankruptcy petition is filed. ${ }^{2}$

The key idea here is that bankruptcy institutions should reward monitors when and only when they

\footnotetext{
' See, for example, Jackson (1986), Jensen (1991), and Gertner and Scharfstein (1991).

${ }^{2}$ Several recent papers emphasize a similar point - that absolute priority violations may be welfare improving. Harris and Raviv (1993) show that a bankruptcy court that mandates violations of absolute priority in some states of the world can be part of an optimal financial contract. Eberhart and Senbet (1993) argue that APR violations ameliorate the asset substitution problem when firms are financially distressed, precisely when other incentive control mechanisms like convertible bonds are ineffective. Eberhart, Moore, and Roenfeldt (1990) provide evidence that APR violations are anticipated ex ante.
} 
have performed their duties. A similar argument has been made by Rajan and Winton (1994), who analyze how the choice of different priority and term structures in loan contracts affects the incentives of lenders to monitor the firm. They argue that informational conditions determine which structures provide the best monitoring incentives, meaning that the firm's capital structure can be used to achieve outcomes that are not directly contractible. In other words, ex ante efficiency is improved by choosing a capital structure that properly rewards monitors.

In addition, our model implies that the preference section of the bankruptcy code should be used with extreme discretion. Preference law, as it relates our problem, is designed to prevent claimants from opting out of the collective proceeding by nullifying payments made to some creditors immediately prior to the bankruptcy filing. ${ }^{3}$ Our results suggest that such actions by a bankruptcy judge would in fact reduce the incentive to monitor, lowering social welfare.

The next section summarizes traditional bankruptcy analyses. Here we outline some of the standard arguments that an alternative to FCFS rules in bankruptcy law is needed, and question whether these arguments are valid in all circumstances. We then use this background to analyze other studies of bankruptcy. In section II, we introduce our model and show that under certain conditions, a firm may be unable to obtain financing because it cannot commit ex ante to a low-risk project; possible solutions to this problem are analyzed. In particular, we show that a mixed-strategy equilibrium exists in which the firm is able to find lenders. Section III looks at the effect different bankruptcy rules may have on the equilibrium of this game. We show that PPRs reduce the incentive of lenders to monitor the firm, thus raising the social cost of these contracts. Section IV extends the model to allow lenders to designate a monitor. As before, PPRs undercompensate the designated monitor (called a bank) for its services, leading to a less efficient outcome than do FCFS rules. We then show that strict seniority for the designated monitor is also Pareto inferior, since it overcompensates the monitor. We conclude in section $\mathrm{V}$ by

\footnotetext{
${ }^{3}$ See Jackson (1986), chapter 6.
} 
examining features of standard loan contracts that look much like the FCFS rules of our model. We also examine two recent examples of these rules in action. Finally, we discuss the theoretical and policy implications of our model and propose some possible extensions to our results. Several of the proofs are relegated to the appendix.

\section{Section I - Justifications for PPRs}

Most discussions of bankruptcy institutions start with the assumption that a formal procedure for distributing the assets of an insolvent firm is needed, and then focus on the specific form such a procedure should take. But it is not clear that this assumption is valid in all cases. To see this, consider some of its standard justifications.

In the absence of bankruptcy laws, assets are distributed to creditors in the order in which they have staked their claims. Thus, the first lender to request repayment is, generally, the first to receive payment. Lenders who end up last in line are paid last and quite possibly receive nothing. For this reason, these default bankruptcy proceedings are typically called FCFS rules.

Traditional rationales for a more orderly mechanism cite several potential problems with FCFS rules. First, lenders may wish to protect their position by expending excessive resources monitoring the firm's condition. If a lender does not do this, the argument goes, he will certainly be the last to know when the firm is about to default, and thereby be last in line to collect his claim. Furthermore, since all lenders are engaged in this monitoring, no one will get a more preferable place in line than he would if none of them monitored, so these resources are spent in vain. This game looks much like the classic prisoners' dilemma, in which the Pareto superior outcome with no monitoring is not a Nash equilibrium. It is argued that an orderly bankruptcy procedure allows lenders to avoid these costs, making all of them better off.

A second argument against FCFS rules is the classic "common pool" problem. Here it is claimed 
that in their rush to be paid, lenders might reduce the total liquidation value of the firm by separating assets that would be more valuable together. An orderly liquidation, on the other hand, would ensure that the firm's assets are put to their most productive uses, maximizing their value to the creditors. Worse yet, lenders might actually run too soon and foreclose on illiquid but otherwise viable firms. Here again, formal bankruptcy rules should help prevent these inefficient liquidations.

Jackson (1986), p. 10, summarizes the intuition behind these arguments: "The basic problem that bankruptcy law is designed to handle ... is that the system of individual creditor remedies may be bad for the creditors as a group when there are not enough assets to go around."

With these (often implicit) assumptions, modern examinations of bankruptcy rules investigate what form formal liquidation rules should take. For example, many authors have looked at the relative efficiency of APRs (where the order of repayment is determined ex ante by assigning each lender a priority level) and PPRs. ${ }^{4}$ Under various assumptions, they all conclude that these rules are inefficient in regard to both the liquidation/continuation decision and the decision to make new investments. Numerous other studies look directly at the Chapter 11 Bankruptcy Code and show that, in general, it does not provide efficient investment or liquidation incentives either. ${ }^{5,6}$

But none of these studies examines the relative efficiency of various bankruptcy rules compared to the natural default - FCFS rules. We believe that a formal examination of the efficiency of FCFS rules is a necessary starting place for analyses of bankruptcy.

In addition, most models analyze the effects of bankruptcy ex post. They begin with a firm having some existing capital structure that is unable to meet its current debt obligations. The focus is on whether

${ }^{4}$ See, for example, Bulow and Shoven (1978), White (1980, 1983), and Gertner and Scharfstein (1991).

${ }^{5}$ Detragiache (1991) and Gertner and Scharfstein (1991) are two among many examples.

${ }^{6}$ For further information on bankruptcy and financial distress and their impact on incentives, see Aghion and Bolton (1992), Berkovitch and Israel (1991), Berkovitch and Kim (1990), Berlin and Mester (1992), Hart and Moore (1989), Jensen and Meckling (1976), and Myers (1977). 
or not different bankruptcy rules provide proper incentives so that creditors will foreclose if and only if the firm is insolvent, and will extend new credit to the firm for and only for positive net present value projects. Whether bankruptcy rules provide for decisions that are efficient ex post is certainly an interesting question. But debt contracts are designed to resolve ex ante uncertainty, and their efficiency must therefore be measured from the viewpoint of the initial contracting problem. Indeed, most of the literature on asymmetric information accepts ex post inefficiency in some states of the world in order to achieve an outcome that is ex ante Pareto optimal. The proper question, then, is how different bankruptcy rules affect the social cost of debt contracts at the time in which they are written.

Boyes, Faith, and Wrase (1991) is one of few papers to address both of these issues. They compare the ex ante social cost of debt contracts under PPRs and FCFS rules and conclude that the PPRs found in Chapter 7 are more efficient than FCFS rules, since they reduce the cost of contracting. Their result depends upon the assumption that rushing to liquidate the firm is costly, whereas formal bankruptcy proceedings are not. In a FCFS world, lenders must pay to enter a queue to obtain the firm's assets. If they allow a firm to continue despite the fact that its expected return is negative, they will avoid these queuing costs some of the time (when the firm does well). Thus, lenders have an incentive to allow some firms with negative net present value to continue. ${ }^{7}$

Their model differs from ours in several important respects. First, they assume that FCFS rules are more costly to implement than are PPRs. As a result, this model simply shows that the more costly course of action is the less efficient one. ${ }^{8}$ More important, in our model the firm chooses between two different investment projects. This choice is the private information of the firm, creating a moral hazard

\footnotetext{
${ }^{7}$ They also acknowledge that FCFS rules may result in inefficient liquidations of firms that have a positive net present value, and claim that this gives further support to their argument that PPRs are more efficient. They ignore, however, the possibility that these two effects may offset each other, reducing the net inefficiency of FCFS rules.

${ }^{8}$ If they were to assume that both types of rules entailed the same costs, their model would indicate that FCFS rules are preferred, since they involve these costs only a fraction of the time, whereas PPRs always do.
} 
problem which requires lenders to monitor it. When there are many lenders, they may wish to free ride on the monitoring efforts of each other. We propose that FCFS rules can serve to ameliorate this problem.

Some of our conclusions resemble those of Diamond (1992), who finds that when a firm cannot negotiate with its long-term (public) lenders, short-term (bank) lenders should be made junior, to reduce their incentive to liquidate the firm early. ${ }^{9}$ His model differs from ours, however, in several important respects. His is an adverse selection model, and the monitoring that occurs in the interim phase is costless. In addition, it is a noisy signal of the firm's true type. More important, efficiency in his model depends upon the proper continuation/liquidation decision in the interim period. In other words, he looks at ex post rather than ex ante efficiency.

\section{Section II - The Model}

Consider a three-period model with a risk-neutral firm. In the first period, the firm has the opportunity to invest in only one of two projects, each of which has a random return in period three. ${ }^{10}$ Denote these projects $G$ and $B$ to coincide with their respective distribution functions. ${ }^{11}$ Assume that both projects have the same mean, but that project $G$ is second-order stochastic dominant over $B$, i.e, that

$$
\int_{\underline{x}}^{\gamma}[G(x)-B(x)] d x \leq 0, \quad \forall \gamma \in[\underline{x}, \bar{x}],
$$

${ }^{9}$ See also Diamond (1990a, 1990b, 1991).

${ }^{10}$ Alternatively, we could assume that the owner of the firm must choose one of two levels of effort.

${ }^{11}$ Unless otherwise stated, we will assume in what follows that both distributions have the same support, $[\underline{x}, \bar{x}]$. This assumption is for notational simplicity and is not necessary, since we assume that project revenues cannot be observed by lenders outside of default. If they could be observed and the projects had different supports, then it would be possible to ensure efficient investment by writing contracts that impose large penalties on the firm when outcomes that could not have resulted from the designated project are observed. 
with strict inequality for a set of values of $x$ with positive probability. ${ }^{12}$ Thus, $B$ is more risky than $G$ in the sense of Rothschild-Stiglitz (1970). ${ }^{13}$ Furthermore, the choice of project and the resulting revenue in period three are costlessly observable only by the firm. Outsiders may discover the choice of project in period two only by paying a cost, $c$. The results of this monitoring provide a perfect signal of the firm's choice of project.

Both projects require $L$ dollars to undertake. Because the firm has no resources of its own, it must raise external financing. Equity is out of the question, since the revenue from these projects cannot be publicly observed. ${ }^{14,15}$ Consequently, the firm must borrow this initial investment. We will assume that the loan market is composed of a large number of identical risk-neutral agents, each with an endowment of $L / n$. This endowment may be either loaned to the firm or invested in a riskless technology with a return of 1 . In equilibrium, competition will always drive down the interest rate to ensure that all lenders

\footnotetext{
${ }^{12}$ The fact that the two projects have equal means implies that, in the absence of transaction costs, both projects would be useful. However, our informational asymmetry makes project $B$ less socially desirable, since it has higher expected bankruptcy costs.

This condition is not necessary for the conclusions that follow, but it simplifies the proof of Proposition 2 . This proposition will still hold if project $G$ has a higher mean than does project $B$, provided that the spread is not too large. Thus, all our results would still hold even if project $B$ were a negative net present value project.

${ }^{13}$ For a good introduction to the Rothschild-Stiglitz definition of increasing risk, see Laffont (1989).

${ }^{14}$ Here we are appealing to the classic costly state verification model of Townsend (1979). More recently, Gale and Hellwig (1985), Boyd and Smith (1993a), Dionne and Viala (1992), Krasa and Villamil (1994), and Winton (1992) have demonstrated the general robustness of this result. Of particular interest are Boyd and Smith and Dionne and Viala, both of whose models are similar to our own. Boyd and Smith complicate the costly state verification story by introducing adverse selection (in order to study credit rationing), whereas we focus on a moral hazard problem. Dionne and Viala use costly effort (as opposed to second-order stochastic dominance) to introduce the moral hazard problem.

Note that the monitoring we discuss below is distinct from the state verification of these models. In our context, monitoring is an action that takes place before the outcome of the project is determined; state verification occurs after the project's return is realized.
}

${ }^{15}$ Recent extensions to the costly state verification literature indicate that stochastic verification may dominate the deterministic verification assumed here. Since the declaration of bankruptcy seems to occur deterministically in real life, we are not too uncomfortable ruling out randomization at this stage of the game. In addition, we are comforted by the results of Boyd and Smith (1993b), who conclude that the relative size of any welfare loss from this restriction is small and that incentive problems associated with randomization schemes may very well make them suboptimal. 
make zero profits. Figure 1 shows the order of events in this economy.

\begin{tabular}{|c|c|c|}
\hline Period 1 & Period 2 & Period 3 \\
\hline $\begin{array}{c}\text { Loans Made } \\
\text { Project Selected }\end{array}$ & $\begin{array}{c}\text { Short-Term Debt Due } \\
\text { Monitoring Occurs }\end{array}$ & $\begin{array}{l}\text { Long-Term Debt Due } \\
\text { Project Matures }\end{array}$ \\
\hline
\end{tabular}

Figure 1 - Sequence of Events

\section{Long-Term Debt}

To finance either of these "long-term" projects, the firm could issue long-term debt — that is, debt that comes due in period three. If the firm commits to invest in a particular project, any prospective lender will demand a default premium commensurate with that project's anticipated risk. Let $x$ be the project's realized value. If $r$ is the promised interest rate, then the firm must default if $x<r L$. The liquidation proceedings that follow default, or state verification, cost $d(r L-x)$, where $d$ is some positive constant. Thus, the dead-weight cost of default depends upon its magnitude and is equal to zero when the firm can just pay its debts. ${ }^{16}$

If the firm chooses to invest in project $G$, each lender's expected return is

$$
\frac{1}{n} \int_{\underline{x}}^{\bar{x}}(\min \{x-d(r L-x), r L\}-L) d G(x) .
$$

Setting this expression equal to zero gives us an equation which implicitly determines the zero-profit interest rate for this project, $r_{G}$. On the other hand, if the firm chooses project $B$, each lender's expected

\footnotetext{
${ }^{16}$ More generally, we could assume that $d(\cdot)$ is some arbitrary function of the size of default $r L-x$. In this case, the restriction in Proposition 1 would be that $d^{\prime}(\cdot)$ be sufficiently small - i.e., that the cost of default not rise too steeply as its magnitude increases. All of our results would follow using this generalization.

We will also assume that $d(r L-\underline{x}) \leq \underline{x}$ so we can ignore outcomes where the project's returns are insufficient to pay the default costs. This does not affect our results and simplifies the analysis. Alternatively, we could assume that when default occurs, the lender must pay these costs even if they exceed the revenue from the project.
} 
return is

$$
\frac{1}{n} \int_{\underline{x}}^{\bar{x}}(\min \{x-d(r L-x), r L\}-L) d B(x),
$$

which implies a zero-profit interest rate $r_{B} \cdot{ }^{17}$ It is straightforward to show:

PROPOSITION 1: If project $B$ is more risky than project $G$ (in the sense of Rothschild-Stiglitz), and if $d$ is sufficiently small, then $r_{B}>r_{G}$.

Proof: See appendix.

One might be surprised that this proposition depends upon $d$ being small — we would expect that an increase in the interest rate should unambiguously raise the lender's expected return. However, this increase might cause the borrower to default more often, thereby decreasing the lender's return. Stiglitz and Weiss (1981) show that this effect can lead to credit rationing. ${ }^{18}$ Our restriction on $d$ is a mild technical assumption to ensure that this problem will not arise.

The firm's expected profit from projects $G$ and $B$ is

$$
\int_{\underline{x}}^{\bar{x}} \max \left\{x-r_{G} L, 0\right\} d G(x)
$$

and

${ }^{17}$ An example may make the results that follow more clear. Suppose that the support of $G$ and $B$ is $\{1,2,3\}$, with $g(1)=g(3)=.0001, g(2)=.9998, b(1)=b(3)=.4999$, and $b(2)=.0002$. Clearly, these two distributions have the same mean, and $B$ is more risky in the sense of Rothschild-Stiglitz. Let $c=.001, d=.5, n=10$, and $L=1.5$. Setting (2.2) and (2.3) each equal to zero and substituting in these parameters allows us to calculate $r_{G}=1.00005$ and $r_{B}=2.0$.

${ }^{18}$ Our moral hazard story is equivalent to what Stiglitz and Weiss call the "the interest rate as an incentive mechanism." See also Longhofer (1994). 


$$
\int_{\underline{x}}^{\bar{x}} \max \left\{x-r_{B} L, 0\right\} d B(x),
$$

respectively.

Since project $B$ is successful less frequently than is project $G$, given any $d$ the expected cost of default will be higher under project $B$. If the chance of default is sufficiently high, debt financing will be too expensive and the firm will forgo the project (recall that the firm may undertake only one of the two projects). We will assume that the good project is safe enough to ensure that (2.4) is positive, while the bad project is so risky that (2.5) is non-positive (i.e., that $r_{B} L>\bar{x}$ ). In other words, $r_{B}$ is so high that the firm is unable to make positive expected profits. ${ }^{19,20}$ Nevertheless, it is easy to show:

PROPOSITION 2: If project $B$ is more risky than project $G$ (in the sense of Rothschild-Stiglitz), then given any promised payment, the firm will always prefer project $B .^{21}$

Proof: See appendix.

This proposition implies that long-term debt prevents the firm from credibly promising to invest in the less risky project. Once it receives the (relatively low) interest rate associated with $G$, it would like to go ahead and invest in $B$, since it suffers none of the losses associated with the increased variability of the project. If long-term debt is the only option, no lender will accept any interest rate below $r_{B}$, and

\footnotetext{
${ }^{19}$ Since project $B$ has the same expected return as project $G$ under full information, this implies that debt creates an underinvestment problem. This is not a necessary feature of the model. All of our results can be proved under the assumption that $B$ is a negative net present value project, eliminating this implied inefficiency.

${ }^{20}$ In our example started in footnote 17 , the firm's expected profit from project $G$ is .499975 , whereas its expected profit would be zero if it were to undertake project $B$.

${ }^{21}$ This proposition is verified by our example: If the firm were unconditionally offered the good interest rate $\left(r_{g}=1.00005\right)$, its expected profit from selecting the bad project would be .749912 , which is higher than the expected return from selecting the good project.
} 
no project will be undertaken.

This inability of the firm to commit to the less risky project obviously entails social costs. Since $r_{G}$ ensures that lenders make zero profits, the total cost to society is measured by the profits the firm would make under project $G$, given by expression (2.4):

$$
\int_{\underline{x}}^{\bar{x}} \max \left\{x-r_{G} L, 0\right\} d G(x) .
$$

\section{Short-Term Debt}

Is it possible to avoid this cost? One solution to this moral hazard problem is a maturity mismatch with short-term debt. ${ }^{22}$ Suppose the firm must make a payment to its lenders in period two. Since the firm has no revenues until period three, it must either default or convince the lenders to roll over its debt. Prior to renewing the debt, however, lenders can monitor the firm and determine which project has been selected. We will assume that potential lenders are diverse and uncoordinated and thus unable to decide ex ante who should perform the monitoring. ${ }^{23}$ To analyze this situation, we will assume that each lender has equal priority and look for a symmetric mixed-strategy Nash equilibrium.

When the firm receives its financing in period one, it decides how often it will invest in each of the two projects. Let $\pi \in[0,1]$ be the probability that project $B$ is selected. In period two, lenders must decide how often they will monitor the firm, i.e., pick a monitoring probability $\alpha \in[0,1]$. Since we are looking for a symmetric equilibrium, the total probability that the firm is monitored is $1-(1-\alpha)^{n}$.

Conditional on the result of his own monitoring (if it occurs), each lender can then decide whether

${ }^{22}$ Dionne and Viala (1992) also note that short-term debt can be used to ameliorate moral hazard problems. However, they assume that the action selected by the agent (or in our case, the project selected by the firm) is costlessly observable.

${ }^{23}$ In section IV, we show that our results remain essentially unchanged even when all monitoring tasks are delegated to one lender. 
or not to renew his loan. Since the firm has no cash assets in period two, whenever any lender chooses to demand repayment, the firm is liquidated unless it can obtain altemative financing to pay off its old debt.

Let $z$ be the (post-bankruptcy cost) period-two liquidation value of the firm. We assume that $z<L$, so that this value is insufficient to pay off all of the firm's debts. Lenders who monitor are the first in line for the firm's assets when it is liquidated, since they are the first to be aware that the firm has cheated. Thus, under FCFS rules, the firm's assets, $z$, are first divided among the monitors, with nonmonitors receiving a share only after all monitors' claims are paid in full. If instead PPRs are in effect, the liquidation value of the firm is divided equally among all creditors, regardless of whether they monitored.

Finally, if the firm is not liquidated in period two, its project matures and revenues are received in period three. If the firm is able to pay off all lenders, it keeps the balance; otherwise, it is liquidated and its residual value is divided equally among the creditors. ${ }^{24}$

\section{Derivation of an Equilibrium}

We now look for a symmetric equilibrium. In equilibrium, the probability of monitoring, $\alpha$, must make the firm indifferent between choosing project $G$ and project $B$ :

$$
\int_{\underline{x}}^{\bar{x}} \max (x-r L, 0\} d G(x)=(1-\alpha)^{n} \int_{\underline{x}}^{\bar{x}} \max \{x-r L, 0\} d B(x) .
$$

The retum to each lender will depend upon the number of other lenders who monitor. Let $M(w)$ denote the probability that $w$ of the other lenders monitor the firm in period two. Clearly, $w$ has a binomial distribution so that

\footnotetext{
${ }^{24}$ Note that in period three, no lender has advance information that the firm will default. Thus, all lenders have equal priority in this period. We show in section $\mathrm{V}$ that strict priority rules which govern the distribution of assets both in this period and in period 2 are inefficient.
} 
clevelandfed.org/research/workpaper/index.cfm

$$
M(w)=\left(\begin{array}{c}
n-1 \\
w
\end{array}\right) \alpha^{w}(1-\alpha)^{n-1-w}
$$

Given that all other lenders behave in the same way, the expected return to a lender who monitors is

$$
(1-\pi) R_{G}(r)+\pi \xi_{1}(r)-c-\frac{L}{n}
$$

where

$$
R_{G}(r)=\frac{1}{n} \int_{\underline{x}}^{\bar{x}} \min \{x-d(r L-x), r L\} d G(x)
$$

is the lender's expected return when the firm chooses project $G$, and $\xi_{1}$ is the expected return to a lender who monitors when the firm "cheats." Under PPRs, this is just the period-two liquidation value of the firm divided by the number of lenders, so:

$$
\xi_{1}^{P P R}=\frac{z}{n}
$$

With FCFS rules, this return depends upon the number of other lenders with whom the liquidation value of the firm must be shared. If $z$ is large enough, each lender receives $L / n$, the principal value of the loan. Otherwise, the monitoring lenders divide $z$ equally among themselves. This gives us

$$
\xi_{1}^{F C F S}=\sum_{w \infty 0}^{n-1} M(w) \min \left\{\frac{z}{w+1}, \frac{L}{n}\right\} .
$$

On the other hand, the expected return to a lender who does not monitor is

$$
(1-\pi) R_{G}(r)+\pi(1-\alpha)^{n-1} R_{B}(r)+\pi \xi_{2}(r)-\frac{L}{n},
$$

where $R_{B}(r)$ is defined like $R_{G}(r)$, and $\xi_{2}$ is the expected return to a non-monitoring lender when the firm is liquidated in period two. Under PPRs,

$$
\xi_{2}^{P P R}=\left[1-(1-\alpha)^{n-1}\right] \frac{z}{n},
$$

while under FCFS rules, 


$$
\xi_{2}^{F C F S}=\sum_{w=1}^{n-1} M(w) \max \left\{\frac{z-w L / n}{n-w}, 0\right\} .
$$

The intuition behind (2.12) is as follows: The first term is the lender's expected return when the firm chooses project $G$. If the firm instead chooses project $B$, the lender's expected return depends upon the monitoring decisions of the other lenders. If none of them monitor, then all lenders roll over their debt and the firm continues until period three, giving us the second term. Finally, if at least one of the other lenders monitors the firm, it is liquidated, and lenders who don't monitor expect to receive the third expression.

Define $\alpha_{s}$ as the solution to (2.6), and $\pi_{s}$ and $r_{s}$ to be the probability of monitoring and the interest rate that simultaneously solve (2.8) and (2.12) equal to zero. Then we have the following characterization of equilibrium:

PROPOSITION 3: When the period-two liquidation value of the firm, $z$, is sufficiently large, the following strategies constitute a mixed-strategy Nash equilibrium with short-term debt:

(1) The firm chooses project $B$ with probability $\pi_{s}$, and project $G$ with probability $\left(1-\pi_{s}\right)$;

(2) Lenders choose to monitor with probability $\alpha_{s}$, and refuse to renew their loans only when they observe project $B$; and

(3) All outsiders assume that the firm has chosen project $B$ with probability one whenever it seeks new financing in period two.

Proof: See appendix.

An examination of the proof of Proposition 3 provides some intuition on the required lower bound on the period-two liquidation value of the firm: $z$ must be larger than the sum of lenders' expected returns from allowing a "bad" firm to continue. That is, if lenders as a group expect to receive more from 
allowing the riskier firm to continue, they will do so, and these strategies will not be an equilibrium. This is a natural parametric restriction. ${ }^{25}$

In the next section, we show that this contract is less likely to exist under PPRs than it is under FCFS rules, and that when it does exist, it is more costly to implement.

\section{Section III - Existence and Efficiency of Equilibrium}

The equilibrium developed in the previous section was derived in a manner consistent with both FCFS rules and PPRs. Our goal in this section is to show that 1) equilibrium is less likely to occur under PPRs, and 2) when it does exist, the total social cost of the contract will be higher under PPRs. We do this by examining the interest rate in this problem under each of these rules.

In order for equilibrium to exist, $\alpha_{s}$ must solve (2.6):

$$
\int_{\underline{x}}^{\bar{x}} \max \{x-r L, 0\} d G(x)=(1-\alpha)^{n} \int_{\underline{x}}^{\bar{x}} \max \{x-r L, 0\} d B(x),
$$

and $\pi_{s}$ and $r_{s}$ must solve both

$$
(1-\pi) R_{G}(r)+\pi \xi_{1}(r)-c-\frac{L}{n}=0
$$

and

$$
(1-\pi) R_{G}(r)+\pi(1-\alpha)^{n-1} R_{B}(r)+\pi \xi_{2}(r)-\frac{L}{n}=0
$$

In addition, the following conditions must be satisfied: $0 \leq \alpha_{s} \leq 1,0 \leq \pi_{s} \leq 1$, and $1 \leq r_{s} \leq \bar{x} / L{ }^{26}$

\footnotetext{
${ }^{25}$ The lower bound on $z$ is more stringent under PPRs than it is under FCFS rules, implying that this equilibrium exists for a smaller range of parameter values under PPRs ( $z$ can be smaller under FCFS rules). This reinforces our claim that FCFS rules dominate PPRs (see section III).

${ }^{26}$ Proposition 2 implies that $\alpha_{s}$ is always positive. Moreover, it will be less than one whenever project $G$ is profitable for the firm.
} 
THEOREM 1: The interest rate is higher under PPRs than it is under FCFS rules.

Proof: See appendix.

The intuition behind Theorem 1 is straightforward and is illustrated in figure 2 . Let $\pi_{1}$ be the locus of $(\pi, r)$ pairs that solve (3.2) and $\pi_{2}$ be the locus solving (3.3). The left-most intersection of these loci is our equilibrium. ${ }^{27}$

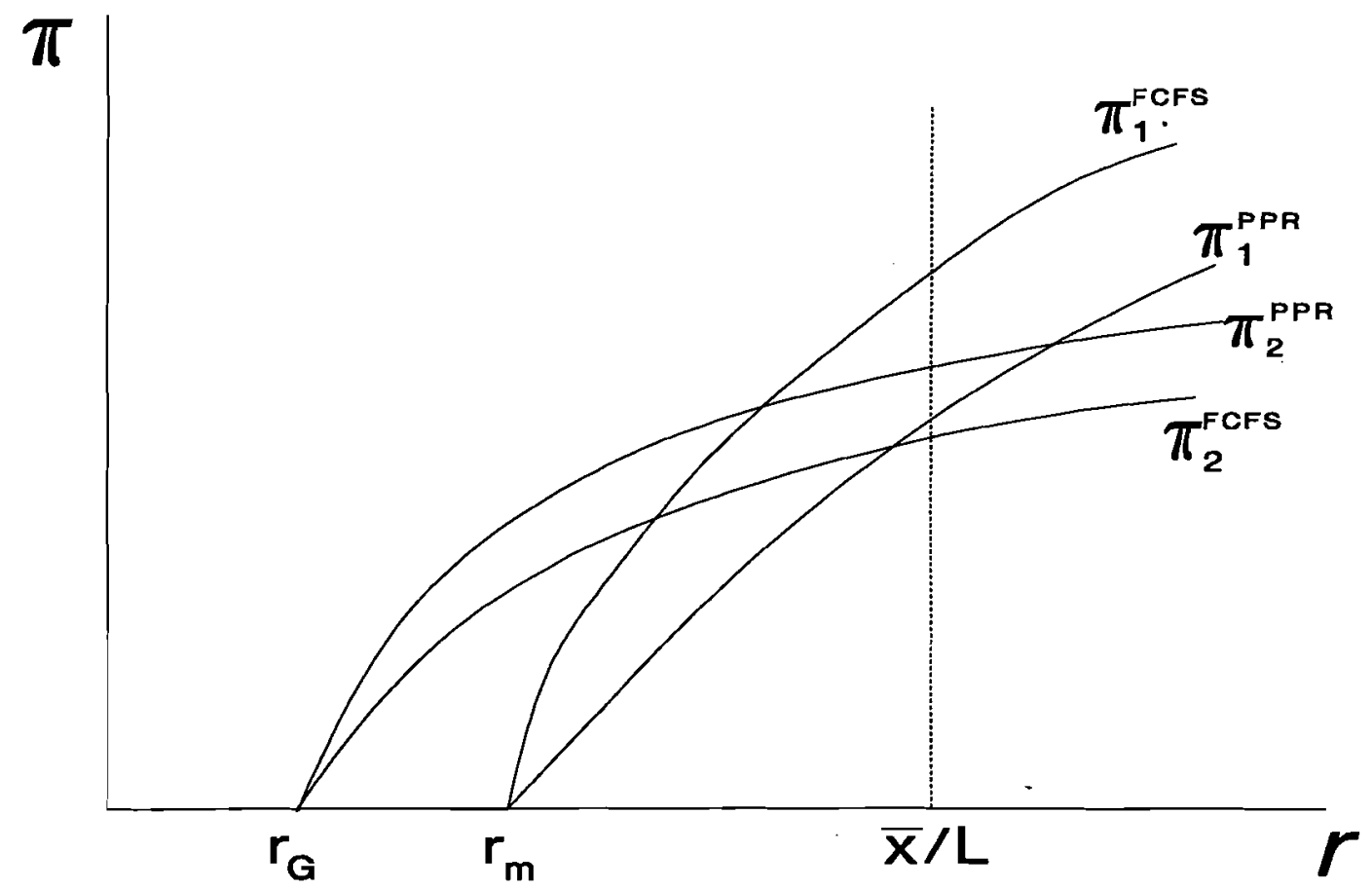

Figure 2

When the firm is caught investing in project $B$, FCFS rules give more to lenders who monitor than do PPRs. Thus, $\pi_{1}^{F C F S}$ is everywhere above $\pi_{1}^{P P R}$. Similarly, when the firm is caught cheating, lenders who don't monitor receive less under FCFS rules than they do under PPRs: PPRs allow lenders to free

${ }^{27}$ Since any such intersection provides lenders with zero expected profit, the equilibrium is the one that results in the lowest possible interest rate for the borrower, i.e., the left-most intersection. 
ride on the monitoring efforts of others. Hence, $\pi_{2}^{F C F S}$ is everywhere below $\pi_{2}^{P P R}$. This implies that the first intersection of these two curves under PPRs must be to the right of the first intersection under FCFS rules, so the equilibrium under FCFS rules must entail a lower interest rate. ${ }^{28}$

It is immediately clear that equilibrium is less likely to exist under PPRs:

COROLLARY: Existence of an equilibrium is less likely under PPRs than it is under FCFS rules.

Proof: For the less risky project to be feasible, the total payment made by the firm, $r_{s} L$, must be less than $\bar{x}$, the project's largest possible outcome. ${ }^{29}$ As $r$ increases, this condition is less likely to be satisfied.

Basically, the shifts in $\pi_{1}$ and $\pi_{2}$ due to the change in bankruptcy rules make an intersection between them less likely to occur within our relevant range. As shown in figure $2, \bar{x} / L$ is the highest value the interest rate can take and still allow the firm to make non-negative profits. Since $\pi_{1}^{P P R}$ and $\pi_{2}^{P P R}$ first intersect at an interest rate higher than $\bar{x} / L$, an equilibrium does not exist under PPRs (in this example).

Also note that Proposition 3 implies equilibrium is less likely to exist under PPRs. That proposition required that the period-two liquidation value of the firm exceed the sum of the lenders' expected returns from allowing project $B$ to mature. Under FCFS rules, this critical $z$ is smaller than it

\footnotetext{
${ }^{28}$ Let us again turn to the example that we started in footnote 17 . If we assume $z=1.4$, direct calculation verifies that when FCFS rules are in effect the interest rate is 1.00695 , while under PPRs it is 1.01092 .

${ }^{29}$ Strictly speaking, this bound may be even lower. If $d$ is sufficiently large, credit rationing will appear, reducing the maximal feasible interest rate. In this case, however, it is the lenders who will refuse to participate. See Longhofer (1994) for a more detailed examination of this type of credit rationing.
} 
is under PPRs, meaning that equilibrium will exist for more values of $z$ under FCFS rules than under PPRs. $^{30}$

Even when an equilibrium does exist under both types of bankruptcy proceedings, we can show that the equilibrium under FCFS rules Pareto dominates that arising under PPRs. ${ }^{31}$

THEOREM 2: Total surplus is larger under FCFS rules than under PPRs.

Proof: Since lenders make zero profits under both procedures, total surplus is measured by the firm's expected profits:

$$
\left(1-\pi_{s}\right) \int_{\underline{x}}^{\bar{x}} \max \left\{x-r_{s} L, 0\right\} d G(x)+\pi_{s}\left(1-\alpha_{s}\right)^{n-1} \int_{\underline{x}}^{\bar{x}} \max \left\{x-r_{s} L, 0\right\} d B(x) .
$$

When $r_{s}^{\prime}$ changes, (2.6) implies that $\alpha_{s}$ adjusts so as to keep:

$$
\int_{\underline{x}}^{\bar{x}} \max \left\{x-r_{s} L, 0\right\} d G(x)=\left(1-\alpha_{s}\right)^{n-1} \int_{\underline{x}}^{\bar{x}} \max \left\{x-r_{s} L, 0\right\} d B(x) .
$$

As a result, any change in $\pi_{s}$ is irrelevant - it merely changes the relative weights placed on two equal quantities. But increases in the interest rate lower both terms in (3.4) because:

$$
\frac{d}{d r} \int_{\underline{x}}^{\bar{x}} \max \{x-r L, 0\} d G(x)=-L[1-G(r L)]<0 .
$$

Since $r_{s}$ is higher under PPRs, firm profits must be higher under FCFS rules.

\footnotetext{
${ }^{30}$ In our example, $z$ must be larger than 1.12917 under PPRs, but it must only be larger than 0.616982 under FCFS rules.

${ }^{31}$ In our example, total social surplus (as defined by the firm's expected profits) is .489619 under FCFS rules, while it is only .48367 under PPRs.
} 
Essentially, PPRs encourage lenders to free ride on the monitoring efforts of others, since these rules give each of them the same claim on the firm's assets regardless of whether or not they monitor. With FCFS rules, lenders do have an incentive to monitor, since it gives them first call on the firm's assets in default. This reduces the interest rate needed to give lenders zero expected profits, letting the firm earn a higher return.

\section{Section IV - Delegated Monitor}

One might argue that FCFS rules result in excessive monitoring of the firm, since monitoring will generally be done by more than one lender. If instead the lenders were to coordinate and name a delegated monitor, total social costs might decline. We show in this section that FCFS rules are preferred to both PPRs and APRs when a delegated monitor is selected.

As before, the firm needs to raise $L$ to finance either project. We will assume that the lender to whom the task of monitoring is delegated (henceforth called the "bank") loans the firm $L_{B}$, with the rest of the investment, $L-L_{B} \equiv L_{P}$, being provided by the $n-1$ non-monitoring ("public") lenders. Since the bank must be compensated for monitoring, the interest rate it receives will in general differ from that paid to the other lenders. Let $r_{B}$ be the interest rate received by the bank, and $r_{P}$ the rate received by all other lenders. Then the total obligation of the firm is

$$
\rho=r_{B} L_{B}+r_{P} L_{P}
$$

As before, the probability that the bank monitors in period two must be set so that the firm is indifferent between the two projects:

$$
\int_{\underline{x}}^{\bar{x}} \max \{x-\rho, 0\} d G(x)=(1-\alpha) \int_{\underline{x}}^{\bar{x}} \max \{x-\rho, 0\} d B(x) .
$$

The interest rate received by public lenders is determined by their zero-profit condition: 


$$
(1-\pi) R_{G}^{P}\left(r_{P}\right)+\pi\left[\alpha \xi_{P}+(1-\alpha) R_{B}^{P}\left(r_{P}\right)\right]-\frac{L_{P}}{n-1}=0
$$

where $R_{G}^{P}$ and $R_{B}^{P}$ are the expected returns to a public lender from the completion of projects $G$ and $B$, respectively. The definition of these functions is analogous to that in section II. $\xi_{P}$ is the expected return to public lenders when the firm chooses project $B$ and is monitored by the bank. Under FCFS rules, public lenders are paid only after the bank receives its entire claim, while under PPRs, all of the firm's assets are divided equally among the lenders. Thus,

$$
\xi_{P}^{F C F S}=\max \left\{\frac{z-L_{B}}{n-1}, 0\right\} \quad \text { and } \quad \xi_{P}^{P P R}=\lambda_{P} z
$$

where $\lambda_{P}=L_{P} /(n-1) L$ is the proportion of the total debt held by an individual public lender. Similarly, we will define $\lambda_{B}=L_{B} / L$ as the portion of the firm's total debt held by the bank.

The bank's interest rate and the probability that the firm chooses project $B$ are determined by the simultaneous solution of the following two equations:

$$
\begin{gathered}
(1-\pi) R_{G}^{B}+\pi \xi_{B}-c-L_{B}=0 \\
(1-\pi) R_{G}^{B}+\pi R_{B}^{B}-L_{B}=0 .
\end{gathered}
$$

As above, $R_{G}^{B}$ and $R_{B}^{B}$ are the bank's expected retums when projects $G$ and $B$ mature, respectively, and $\xi_{B}$ is the bank's retum when it monitors a firm choosing project $B$. Under FCFS rules, the bank receives all of the firm's assets in liquidation up to the value of its claim $\left(\xi_{B}^{F C F S}=\min \left\{z, L_{B}\right\}\right)$, while under PPRs, the assets are divided proportionately among all creditors $\left(\xi_{B}^{P P R}=\lambda_{B} z\right)$.

Total surplus is measured by expected firm profit:

$$
(1-\pi) \int_{\underline{x}}^{\bar{x}} \max \{x-\rho, 0\} d G(x)+\pi(1-\alpha) \int_{\underline{x}}^{\bar{x}} \max \{x-\rho, 0\} d B(x) .
$$

Expected profit, and hence social welfare, will be increased whenever $\rho$ is decreased. Our goal is to show that $\rho$ will be smaller under FCFS rules than it is under PPRs. To do so, we consider a slightly simplified version of our model by assuming that the probability of default is unaffected by the interest rate paid to 
each lender, and that the cost of default (state verification) is a constant $d_{.}^{32}$

THEOREM 3: Total surplus is higher under FCFS rules than it is under PPRs.

Proof: See appendix.

COROLLARY: Equilibrium is less likely to exist under PPRs than it is under FCFS rules.

Proof: By Theorem 3, the firm's obligation is higher under PPRs.

Theorem 3 shows that firm profit is higher under FCFS rules when the bank and public lenders have the same priority level. The reason is that FCFS rules compensate the bank for performing its function as a monitor, thereby increasing the amount of this socially desirable activity.

Naive intuition would suggest, then, that banks should be given absolute seniority over public debt. This conclusion is incorrect. Absolute seniority gives the bank first claim on the firm's assets in default, whether or not the bank performs its monitoring duties. Paying the bank more regardless of its actions is no better, from a social welfare viewpoint, than using PPRs. To see this, consider the following. Let project $B$ take the value $\bar{x}$ with probability $p$ and $\underline{x}$ with probability $(1-p)$. Project $G$, on the other hand, has a fixed return of $(1-p) \underline{x}+p \bar{x}$. We will assume that project $G$ 's expected return is

${ }^{32}$ Technically, increasing the payment to one lender increases the probability of default, thereby reducing the expected return to all other lenders, holding constant the interest rate they receive. Generally, this second-order effect is small and does not overwhelm those effects analyzed in the proof. The assumption that the probability of default is unaffected by small changes in the interest rates avoids this problem and simplifies our proofs. Note that this assumption is satisfied for most discrete distributions.

Under this assumption, it can also be shown that all previous propositions hold when the cost of default is a constant $d$. In particular, Proposition 1 holds with no restriction on the size of $d$. Although a constant $d$ introduces a discontinuity into the payoff of the lender at the value of $x$ where default just occurs, the assumption above ensures that no such $x$ will be observed ex post, always making the lender prefer the less risky project. 
sufficiently high that the firm is always able to make its payments in period three. In contrast, if the firm chooses project $B$, it can meet its obligations only when the project is successful. As above, we assume that the cost of state verification is fixed at $d$.

Now the bank's expected return from monitoring is

$$
(1-\pi) r_{B} L_{B}+\pi \xi_{B}^{F C F S}-c-L_{B}
$$

while the retum from not monitoring is

$$
(1-\pi) r_{B} L_{B}+\pi\left[p r_{B} L_{B}+(1-p) \psi_{B}\right]-L_{B}
$$

where $\psi_{B}$ is the bank's expected return when the firm defaults. Under FCFS rules, this is $\lambda_{B}(\underline{x}-d)$, and it is $\underline{x}-d$ when the bank has strict seniority. ${ }^{33}$

The public lenders' expected retum is

$$
(1-\pi) r_{P} \frac{L_{P}}{n-1}+\pi\left[\alpha \xi_{P}^{F C S S}+(1-\alpha)\left(p r_{P} \frac{L_{P}}{n-1}+(1-p) \psi_{P}\right)\right]-\frac{L_{P}}{n-1},
$$

where $\psi_{P}$ is the expected return to the public lender when project $B$ is chosen, is allowed to continue, and fails. Under FCFS rules $\psi_{P}=\lambda_{P}(\underline{x}-d)$, whereas $\psi_{P}=0$ when the bank has strict seniority.

We will now show that when they exist, the equilibrium under FCFS rules Pareto dominates the one with strict seniority.

THEOREM 4: Total surplus is larger under FCFS rules than it is when the bank has absolute priority.

Proof: We will show that $\rho$ is a continuous increasing function of $\Psi_{B}$. Since $\Psi_{B}$ is higher under APRs, firm profit is lower.

Continuity is immediate, so a discrete change in $\psi_{B}$ can be viewed as the limit of a sequence of

\footnotetext{
${ }^{33}$ Note that if $\underline{x}-d>r_{B} L_{B}$, the bank will receive only $r_{B} L_{B}$. But in this case, the bank will never monitor, since the lowest possible outcome of project $B$ is still sufficient to repay the bank. This can never be an equilibrium.
} 
infinitesimal changes.

The change in the firm's obligation is

$$
\frac{d \rho}{d \psi_{B}}=L_{B} \frac{\partial r_{B}}{\partial \pi} \frac{d \pi}{d \psi_{B}}+L_{P}\left(\frac{\partial r_{P}}{\partial \psi_{P}} \frac{d \psi_{P}}{d \psi_{B}}+\frac{\partial r_{P}}{\partial \pi} \frac{d \pi}{d \psi_{B}}\right)
$$

Note that $\psi_{P}=\left(\underline{x}-d-\psi_{B}\right) /(n-1)$, so $d \psi_{P} / d \psi_{B}=-1 /(n-1)<0$. In the proof of Theorem 3, we showed that $\partial r_{B} / \partial \pi$ and $\partial r_{P} / \partial \pi$ are both positive. Using (4.9):

$$
\frac{d \pi}{d \Psi_{B}}=\frac{\pi}{r_{B} L_{B}-\psi_{B}}>0
$$

Using (4.10):

$$
\frac{d r_{P}}{d \Psi_{P}}=\frac{-\pi(1-\alpha)(1-p)}{(1-\pi) \frac{L_{P}}{n-1}+\pi(1-\alpha) p \frac{L_{P}}{n-1}}<0
$$

Combining these results proves $d \rho / d \Psi_{B}>0$.

COROLLARY: Equilibrium is less likely to exist when the bank has absolute priority over public lenders than when FCFS rules are in effect.

Proof: By Theorem 4, the total obligation of the firm is higher under APRs.

With APRs, the problem is exactly the opposite of what it is under PPRs: The bank is being paid too often. The fact that the bank receives first claim on the firm's assets in bankruptcy reduces its incentive to monitor. As a result, the firm chooses the riskier project more frequently, for which lenders must be compensated with a higher interest rate.

The lesson here is simple, but important: In order to properly align monitoring incentives, the bankruptcy procedure should compensate a lender when and only when it monitors the borrower. 


\section{Section V - Conclusions}

This paper has questioned the standard assumption that PPRs within each lender class and absolute priority among classes are always necessary in bankruptcy. In our model, a moral hazard problem makes the act of monitoring a socially beneficial public good. As such, the total cost of debt contracting is reduced when the bankruptcy procedure compensates those lenders who monitor a misbehaving firm. Allowing creditors to "run" on a financially distressed firm to retrieve their assets serves to implement just such a compensation mechanism.

While existing bankruptcy law is generally believed to discourage such firm runs, many contractual arrangements do exist that allow lenders with superior information about a firm's prospects to retrieve their assets before other creditors may be aware of a problem. We now look at two such mechanisms.

The model of section II closely resembles that of a retail firm with many suppliers. Suppliers of retail outlets commonly provide them with trade credit. These loans are typically renewed shortly after they are repaid as new merchandise is purchased by the retailer. However, a creditor may refuse to ship new supplies on credit if it perceives that the firm is in trouble. Thus, the trade creditor looks much like a monitor from section III. By refusing to renew its loan, a trade creditor may force a troubled firm into bankruptcy earlier than it might otherwise have gone, preventing it from taking actions that would further weaken its financial condition.

A prime example of this type of monitoring occurred in November 1991. Heller Financial, Inc., a major factoring company for R.H. Macy \& Co., announced that it would no longer guarantee payment for new goods shipped to the retailer. This announcement turned out to be the first of a series of pressures placed on Macy that ultimately resulted in its filing for Chapter 11 bankruptcy protection on January 27 of the next year. Heller's announcement not only protected it from future losses, but also served as a signal to the rest of the market that Macy's financial problems were becoming critical. 
Another common contractual arrangement is the right of acceleration and setoff a bank may exercise when it discovers a borrower has breached a clause of its loan agreement. If the bank observes some breech of the loan agreement, it can accelerate the loan and seize the borrower's deposits and other assets on account with the bank, thereby ensuring at least partial repayment. This aspect of the loan agreement looks much like the FCFS contracts considered in section IV. Here, the bank is compensated when it does monitor the firm and detects a problem early. If the bank is not diligent, however, the distressed firm will file for Chapter 11 bankruptcy protection, thereby nullifying the right of setoff.

An example of this type of situation occurred in April 1993 when Fidelity Bank, acting on behalf of a seven-bank group, seized Nutri/System, Inc.'s cash and bank accounts after restructuring talks broke down. This seizure closed 283 of the company's outlets and led its franchisees to force the company into bankruptcy. In addition, it forced Nutri/System's management to relinquish control to a new investor group. As with R.H. Macy \& Co., the action of Fidelity Bank not only compensated it for performing its monitoring duties, but also provided a socially valuable service by forcing Nutri/System to deal with its problems more quickly than it might otherwise have done.

Clearly, these examples are the exception, not the rule, in dealing with financially distressed firms. But this fact supports our contention that these agreements are designed as incentive mechanisms. If they are effective in preventing borrower misbehavior, then they shouldn't be exercised often.

Nevertheless, inefficiencies still exist under all of the bankruptcy rules in our model. Most notably, we have assumed that both projects have a positive net present value, so in a first-best world, both should be undertaken. Debt in our model creates an underinvestment problem. This does not change the fact, however, that FCFS rules are more efficient than the other bankruptcy rules considered. Furthermore, this underinvestment problem is not a necessary feature of our model. All of our results can still be derived when the more risky project has a negative net present value, provided that the spread between the expected retums is sufficiently small. 
Lately, there has been extensive debate about whether or not, and if so how, bankruptcy laws should be reformed. One proposal receiving significant attention is by Aghion, Hart, and Moore (1992) ${ }^{34}$ They suggest that each of a firm's creditors should be given an option to purchase the firm's assets from more senior claimants at the value of their claims. This system would guarantee that a distressed firm's assets end up with the individual or group who values them most, and would ensure that economically viable firms will continue. While this proposal would do much to eliminate the ex post inefficiencies associated with modern bankruptcy proceedings, it does not answer the basic concerns we address in this paper. Like the PPRs and APRs we discuss above, their proposal does not consider the impact a proper compensation scheme can have on the probability that bankruptcy will occur in the first place.

This model is not intended to suggest that existing bankruptcy rules should be discarded. Indeed, our results suggest that some artifacts of Chapter 11 generally viewed as undesirable may in reality provide some benefit. In particular, the fact that junior claimants often maintain some value even when more senior claims are not paid in full is often viewed as a weakness of the law. However, if one assumes that those senior claimants involved in the collective proceeding are those who failed to monitor the debtor, social welfare is increased by failing to pay them the full value of their claims. ${ }^{35}$

The main point we wish to emphasize in the debate over bankruptcy reform is that policymakers should consider the impact of bankruptcy rules not only on the distribution of a financially distressed firm's assets, but also on the terms of debt contracts. It is this latter influence that has the largest effect on social welfare.

\footnotetext{
${ }^{34}$ See also Roe (1983) and Bebchuk (1988).

${ }^{35}$ Some recent papers have demonstrated that deviations from absolute priority may be welfare improving ex ante. See Harris and Raviv (1993) and Eberhart and Senbet (1993).
} 


\section{Appendix}

Proof of PROPOSITION 1: First consider the effect of a change in the interest rate on the lender's expected return from any arbitrary project $F$ :

$$
\frac{\partial R_{F}}{\partial r}=\frac{L}{n}[1-F(r L)-d f(r L)]
$$

Thus, if $d<[1-F(r L)] / f(r L)$, this derivative will be positive, meaning that an increase in the interest rate raises the lender's expected return. This provides the required upper bound for $d$. In general, this relationship is ambiguous, since an increase in the interest rate will also increase the probability of default.

Let $R_{B}\left(r_{G}\right)$ denote the lender's expected return if project $B$ is chosen with interest rate $r_{G}$, and similarly for $R_{G}\left(r_{G}\right)$. Now lenders have a "utility" function of the following form:

$$
u(x)=\min \left\{\frac{x-d(r L-x)}{n}, \frac{r L}{n}\right\}
$$

which is a weakly concave, weakly increasing function. But any agent with such a utility function must have $R_{B}\left(r_{G}\right)<R_{G}\left(r_{G}\right)$ by second-order stochastic dominance, so the zero-profit interest rate for project $B$ must be greater than $r_{G}$.

Proof of PROPOSITION 2: We wish to show that the difference between the expected profit from project $B$ and the expected profit from project $G$ is positive. This difference is

$$
\int_{\gamma}^{\bar{x}}(x-\gamma) d B(x)-\int_{\gamma}^{\bar{x}}(x-\gamma) d G(x)
$$

where $\gamma$ is the total payment promised in period three. Integrating by parts, we see that this equals

$$
\int_{\gamma}^{\pi}[G(x)-B(x)] d x
$$

Now, the condition of equal means, 


$$
\int_{\underline{x}}^{\bar{x}} x g(x) d x-\int_{\underline{x}}^{\bar{x}} x b(x) d x=0
$$

can be integrated by parts to get

$$
\int_{\underline{x}}^{\bar{x}}[G(x)-B(x)] d x=\int_{\underline{x}}^{\gamma}[G(x)-B(x)] d x+\int_{\gamma}^{\bar{x}}[G(x)-B(x)] d x=0 .
$$

This implies

$$
\int_{\gamma}^{\bar{x}}[G(x)-B(x)] d x=-\int_{\underline{x}}^{\gamma}[G(x)-B(x)] d x
$$

Now, the expression on the right is positive because $G$ is less risky than $B$. But the expression on the left is equation (A4), the value to the firm of choosing project $B$ over project $G$.

Proof of PROPOSITION 3: In the text, we derived the equilibrium probability of monitoring, the probability of choosing the more risky project, and the zero-profit interest rate. Here we have only to show that no agent will wish to deviate from his proposed equilibrium strategy.

(1) After observing the more risky project $B$, a lender who monitors might still wish to renew the loan. This will not be the case if the expected return from rolling over the debt is less than that from foreclosing. Under FCFS rules, this requirement is

$$
\sum_{w=0}^{n-1} M(w) \min \left\{\frac{z}{w+1}, \frac{L}{n}\right\} \geq(1-\alpha)^{n-1} R_{B}(r)+\sum_{w=1}^{n-1} M(w) \max \left\{\frac{z-w L / n}{n-w}, 0\right\} .
$$

The left-hand side is the expected return from foreclosing on the loan and depends upon the number of other lenders who monitor: If the period-two value of the firm is sufficient to pay off all monitors, each receives $L / n$; otherwise, the assets are divided equally among them. The right-hand side represents the expected return from rolling over the debt. If no other lender monitors, the firm continues and the lender's expected return is $R_{B}(r)$. Otherwise, the firm is liquidated and the lender receives some of the firm's assets only if all other monitors are paid in full. 
Now notice that the left side of (A8) is always greater than $\frac{z}{n}$. This is clear, since $\frac{z}{w+1}$ takes its smallest value when $w=n-1$, and $z<L$ by assumption. Thus, this inequality will always be satisfied whenever its right-hand side is less than $\frac{z}{n}$. Cross-multiplying by $n$ gives us a lower bound for $z$ :

$$
z \geq n(1-\alpha)^{n-1} R_{B}(r)+n \sum_{w=1}^{n-1} M(w) \max \left\{\frac{z-w L / n}{n-w}, 0\right\} .
$$

A similar lower bound can be derived under PPRs:

$$
\begin{aligned}
\frac{z}{n} & \geq(1-\alpha)^{n-1} R_{B}(r)+\left[1-(1-\alpha)^{n-1}\right] \frac{z}{n} \\
\Rightarrow \quad z & \geq n R_{B}(r) .
\end{aligned}
$$

(2) A lender might refuse to renew the loan even after observing project $G$. This is a suboptimal strategy under both types of bankruptcy rules as long as ${ }^{36}$

$$
\min \left\{z, \frac{L}{n}\right\} \leq R_{G}\left(r_{s}\right) .
$$

Since the firm has chosen project $G$, no other lenders foreclose. Thus, the left-hand side is the payment to a lender who deviates from equilibrium. The right-hand side is the expected return to a monitor who renews the loan. Clearly, $L / n$ is an upper bound for the left-hand side of this inequality. It is also a lower bound for the right-hand side, since $r_{s} \geq r_{G}$, the interest rate that ensures $R_{G}(r)=L / n$. Thus, this inequality will always hold.

(3) A lender might wish to foreclose when it does not monitor. This will not be the case if the expected return from foreclosing,

$$
\left(1-\pi_{s}\right) \min \left\{z, \frac{L}{n}\right\}+\pi_{s} \sum_{w=0}^{n-1} M(w) \min \left\{\frac{z}{w+1}, \frac{L}{n}\right\},
$$

is less than the expected return from rolling over the debt,

\footnotetext{
${ }^{36}$ Technically, the condition under PPRs is $\min \{z / n, L / n\} \leq R_{G}\left(r_{s}\right)$. But since $z / n<z$, the above condition is sufficient for both rules.
} 


$$
\left(1-\pi_{s}\right) R_{G}\left(r_{s}\right)+\pi_{s}\left(1-\alpha_{s}\right)^{n-1} R_{B}\left(r_{s}\right)+\pi_{s} \xi_{2}\left(r_{s}\right)
$$

Now the first term in (A12) is clearly less than $\left(1-\pi_{s}\right) L / n$. Furthermore, the second term is less than $\pi_{s} L / n$, since $\min \left\{\frac{z}{w+1}, \frac{L}{n}\right\} \leq \frac{L}{n}$. Thus, $\frac{L}{n}$ provides an upper bound on (A12). But (A13) must equal $L / n$, since $r_{s}$ and $\pi_{s}$ solve (2.12) equal to zero in equilibrium. This ensures that this inequality will always be satisfied.

(4) The firm might try to refinance its loans using outside lenders in period two. Regardless of the project chosen, however, outside lenders assume that the firm has selected project $B$, so the best interest rate they will accept is $r_{B}$. This, by assumption, gives the firm non-positive profits. Thus, no firm will wish to deviate in this manner.

Proof of THEOREM 1: Rewriting (3.2) and (3.3) from the text:

$$
\begin{gathered}
(1-\pi) R_{G}(r)+\pi \xi_{1}(r)=c+\frac{L}{n}, \\
(1-\pi) R_{G}(r)+\pi\left\{[1-\alpha(r)]^{n-1} R_{B}(r)+\xi_{2}(r)\right\}=\frac{L}{n} .
\end{gathered}
$$

It is easy to show that

$$
R_{G}(r) \geq c+\frac{L}{n} \geq \xi_{1}(r)
$$

and

$$
R_{G}(r) \geq \frac{L}{n} \geq[1-\alpha(r)]^{n-1} R_{B}(r)+\xi_{2}(r)
$$

ensuring that $\pi \in[0,1]$.

We can solve (A14) and (A15) for $\pi$ as functions of the interest rate: 


$$
\pi_{1}(r)=\frac{R_{G}(r)-c-L / n}{R_{G}(r)-\xi_{1}(r)}, \quad \pi_{2}(r)=\frac{R_{G}(r)-L / n}{R_{G}(r)-(1-\alpha)^{n-1} R_{B}(r)-\xi_{2}(r)} .
$$

The intersections of these two functions will give us $(\pi, r)$ pairs that simultaneously solve (2.8) and (2.12) equal to zero. If these curves intersect more than once, the first such intersection is the candidate for equilibrium, since it entails the lowest interest rate.

Now, $\pi_{1}(r)=0$ when $r=r_{m} \equiv R_{G}^{-1}(c+L / n)$, and $\pi_{2}(r)=0$ when $r=r_{G} \equiv R_{G}^{-1}(L / n)$. As $r$ gets larger, these must enter the positive orthant, since $\pi$ is a convex weight. Clearly, $\pi_{1}^{P P R}$ minorizes ${ }^{37}$ $\pi_{1}^{F C F S}$, since $L / n \geq z / n$ and $z /(w+1) \geq z / n$ for all $w \geq n-1$, and $\pi_{2}^{P P R}$ majorizes $\pi_{2}^{F C F S}$, since

$$
\frac{z-w L / n}{n-w}<\frac{z}{n}, \quad \forall w \in\{1, \ldots, n-1\}
$$

But this implies that the first intersection of $\pi_{1}^{P P R}$ and $\pi_{2}^{P P R}$ must lie to the right of the first intersection of $\pi_{1}^{F C F S}$ and $\pi_{2}^{F C F S}$ (see figure 2 in the text). Compared to FCFS rules, then, PPRs must entail a higher interest rate.

Proof of THEOREM 3: Starting from PPRs and switching to FCFS rules, let $d \xi_{B}$ denote change in the bank's expected return when it monitors a firm that chooses project $B$ :

$$
d \xi_{B}=\min \left\{z, L_{B}\right\}-\lambda_{B} z>0
$$

(This must be positive, since $\lambda_{B}<1$ and $z<L$ ). Rewrite $\rho$ as

$$
\rho\left(\xi_{B}\right)=r_{B}\left(\xi_{B}\right) L_{B}+r_{P}\left(\xi_{B}\right) L_{P} .
$$

We will show that $\rho\left(\xi_{B}\right)$ is a continuous decreasing function, meaning that the switch to FCFS rules reduces $\rho$; this reduction increases firm profit and, hence, social surplus.

Continuity is immediate. This means that the impact of the discrete change in $\xi_{B}$ can be calculated using a sequence of infinitesimal changes.

\footnotetext{
${ }^{37}$ That is, for every $r, \pi_{1}^{P P R}(r)<\pi_{1}^{F C F S}(r)$. Similarly, the phrase $\pi_{2}^{P P R}$ majorizes $\pi_{2}^{F C F S}$ means that $\pi_{2}^{P P R}(r)>$ $\pi_{2}^{F C F S}(r), \forall r$.
} 
The change in the firm's total obligation is

$$
\frac{d \rho}{d \xi_{B}}=L_{B} \frac{d r_{B}}{d \xi_{B}}+L_{P}\left[\frac{\partial r_{P} d \xi_{P}}{\partial \xi_{P}} \frac{\partial r_{P}}{d \xi_{B}}+\frac{\partial \pi}{\partial \pi} \frac{d r_{B}}{\partial r_{B}} \frac{d \xi_{B}}{d \xi}\right.
$$

To simplify this expression, we derive each of its terms. Note that $\xi_{P}=\left(z-\xi_{B}\right) /(n-1)$, which implies $d \xi_{P} / d \xi_{B}=-1 /(n-1)$. Using (4.6), we get:

$$
\frac{d \pi}{d r_{B}}=\frac{(1-\pi) \frac{\partial R_{G}^{B}}{\partial r_{B}}+\pi \frac{\partial R_{B}^{B}}{\partial r_{B}}}{R_{G}^{B}-R_{B}^{B}}>0 .
$$

Following the same argument we used in the proof of Theorem 1, we can see that $d r_{B} / d \xi_{B}<0$. From (4.5) and (4.6), we can calculate

$$
\pi_{1}\left(r_{B}\right)=\frac{R_{G}^{B}-c-L_{B}}{R_{G}^{B}-\xi_{B}} \quad \text { and } \quad \pi_{2}\left(r_{B}\right)=\frac{R_{G}^{B}-L_{B}}{R_{G}^{B}-R_{B}^{B}}
$$

respectively. As before, the $r$ that causes $\pi_{1}=0$ is larger than the $r$ making $\pi_{2}=0$, meaning that for every $r<r^{*}$ (the equilibrium interest rate, if it exists), $\pi_{1}(r)<\pi_{2}(r)$. Now an increase in $\xi_{B}$ causes $\pi_{1}(r)$ to be larger for every $r$. As a consequence, the first intersection of $\pi_{1}$ and $\pi_{2}$ moves to the left as $\xi_{B}$ increases; i.e.,

$$
\frac{d r_{B}}{d \xi_{B}}=\frac{-\pi}{(1-\pi) \frac{\partial R_{G}^{B}}{\partial r_{B}}-\left(R_{G}^{B}-\xi_{B}\right) \frac{\partial \pi}{\partial r_{B}}}<0
$$

calculating this derivative using (4.5).

Finally, (4.3) allows us to calculate:

$$
\frac{d r_{P}}{d \pi}=\frac{R_{G}^{P}-\left[\alpha \xi_{P}+(1-\alpha) R_{B}^{P}\right]}{(1-\pi) \frac{\partial R_{G}^{P}}{\partial r_{P}}+\pi(1-\alpha) \frac{\partial R_{B}^{P}}{\partial r_{P}}}>0
$$

and 
clevelandfed.org/research/workpaper/index.cfm

$$
\frac{d r_{P}}{d \xi_{P}}=\frac{-\pi \alpha}{(1-\pi) \frac{\partial R_{G}^{P}}{\partial r_{P}}+\pi(1-\alpha) \frac{\partial R_{B}^{P}}{\partial r_{P}}}<0 .
$$

We now use these expressions to simplify and sign $d \rho$. First, note that $\frac{\partial r_{P}}{\partial \pi} \frac{\partial \pi}{\partial r_{B}} \frac{d r_{B}}{d \xi_{B}}<0$, so

$$
\frac{d \rho}{d \xi_{B}}<L_{B} \frac{d r_{B}}{d \xi_{B}}-\frac{L_{P}}{n-1} \frac{d r_{P}}{d \xi_{P}}
$$

Substituting:

$$
\begin{aligned}
\frac{d \rho}{d \xi_{B}} & <L_{B} \frac{-\pi}{(1-\pi) \frac{\partial R_{G}^{B}}{\partial r_{B}}-\left(R_{G}^{B}-\xi_{B}\right) \frac{\partial \pi}{\partial r_{B}}}-\frac{L_{P}}{n-1} \frac{-\pi \alpha}{(1-\pi) \frac{\partial R_{G}^{P}}{\partial r_{P}}+\pi(1-\alpha) \frac{\partial R_{B}^{P}}{\partial r_{P}}} \\
& <\frac{\pi}{1-\pi}\left[\frac{\alpha L_{P}}{(n-1) \partial R_{G}^{P} / \partial r_{P}}-\frac{L_{B}}{\partial R_{G}^{B} / \partial r_{B}}\right] \\
& =\frac{\pi}{1-\pi}\left[\frac{\alpha L_{P}}{(n-1) \frac{L_{P}}{n-1}[1-G(\rho)]}-\frac{L_{B}}{L_{B}[1-G(\rho)]}\right] \\
& =\frac{\pi}{1-\pi} \frac{\alpha-1}{[1-G(\rho)]} \\
& <0
\end{aligned}
$$

where $G(\rho)$ is the distribution of the good project evaluated at $\rho$. 


\section{References}

Aghion, Philippe and Patrick Bolton. "An 'Incomplete Contract' Approach to Bankruptcy and the Financial Structure of the Firm." Review of Economic Studies, 1992, 59, 473-494.

Aghion, Philippe, Oliver Hart, and John Moore. "The Economics of Bankruptcy Reform." Journal of Law, Economics, and Organization, October 1992, 8(3), 523-546.

Bebchuk, Lucian A. "A New Approach to Corporate Reorganizations." Harvard Law Review, 1988, 101(4), 775-804.

Berkovitch, Elazar and Ronen Israel. "The Bankruptcy Decision and Debt Contract Renegotiations." University of Michigan, Working Paper, 1991.

Berkovitch, Elazar and E. Han Kim. "Financial Contracting and Leverage Induced Over- and UnderInvestment Incentives." Journal of Finance, July 1990, 45(3), 765-794.

Berlin, Mitchell and Loretta J. Mester. "Debt Covenants and Renegotiation." Journal of Financial Intermediation, 1992, 95(2), 95-133.

Boyd, John H. and Bruce D. Smith. "The Equilibrium Allocation of Investment Capital in the Presence of Adverse Selection and Costly State Verification." Economic Theory, 1993a, 3(3), 427-451.

Boyd, John H. and Bruce D. Smith. "The Welfare Costs of Absolute Priority Rules: Stochastic Versus Nonstochastic Monitoring in a Costly State Verification Environment." Federal Reserve Bank of Minneapolis, Working Paper 512, May 1993b.

Boyes, William J., Roger L. Faith, and Jeffrey M. Wrase. "An Efficiency Theory of Bankruptcy Rules." Arizona State University, Working Paper No. 91-8, 1991.

Bulow, Jeremy I. and John B. Shoven. "The Bankruptcy Decision." Bell Journal of Economics, 1978, 9, 437-456.

Calomiris, Charles W. and Charles M. Kahn. "The Role of Demandable Debt in Structuring Optimal Banking Arrangements." American Economic Review, June 1991, 81(3), 497-513.

Calomiris, Charles W., Charles M. Kahn, and Stefan Krasa. "Optimal Contingent Bank Liquidation under Moral Hazard.” University of Illinois, Working Paper, 1991.

Detragiache, Enrica. "The Resolution of Financial Distress under Asymmetric Information: Is There a Need for Chapter 11?" Johns Hopkins University, Working Paper, 1991.

Diamond, Douglas W. "Debt Maturity Structure and Liquidity Risk." University of Chicago, Working Paper No. 275, 1990a.

Diamond, Douglas W. "Seniority and Maturity Structure of Bank Loans and Publicly Traded Debt." University of Chicago, Working Paper No. 308, 1990 b. 
Diamond, Douglas W. "Monitoring and Reputation: The Choice between Bank Loans and Directly Placed Debt." Journal of Political Economy, 1991, 99(4), 689-721.

Diamond, Douglas W. "Bank Loan Maturity and Priority When Borrowers Can Refinance." University of Chicago Working Paper, 1992.

Dionne, Georges and Pascale Viala. "Optimal Design of Financial Contracts and Moral Hazard." University of Montreal, Working Paper, August 1992.

Eberhart, Allan C. and Lemma W. Senbet. "Absolute Priority Rule Violations and Risk Incentives for Financially Distressed Firms." Financial Management, Autumn 1993, 22(3), 101-116.

Eberhart, Allan C., W.T. Moore, and R.L. Roenfeldt. "Security Pricing and Deviations from the Absolute Priority Rule in Bankruptcy Proceedings." Journal of Finance, December 1990, 1457-1469.

Gale, Douglas and Martin Hellwig. "Incentive-Compatible Debt Contracts: The One-Period Problem." Review of Economic Studies, 1985, 52, 647-663.

Gertner, Robert and David Scharfstein. "A Theory of Workouts and the Effects of Reorganization Law." Journal of Finance, September 1991, 46(4), 1189-1222.

Harris, Milton and Artur Raviv. "The Design of Bankruptcy Procedures." Northwestern University, Kellogg Graduate School of Management, Working Paper No. 137, March 1993.

Hart, Oliver and John Moore. "Default and Renegotiation: A Dynamic Model of Debt." Massachusetts Institute of Technology, Working Paper, 1989.

Jackson, Thomas H. The Logic and Limits of Bankruptcy Law. Cambridge, Mass.: Harvard University Press, 1986.

Jensen, Michael C. "Corporate Control and the Politics of Finance." Journal of Applied Corporate Finance, 1991, 4, 13-33.

Jensen, Michael C. and William H. Meckling. "Theory of the Firm: Managerial Behavior, Agency Costs, and Ownership Structure." Journal of Financial Economics, 1976, 3, 305-360.

Krasa, Stefan and Anne P. Villamil. "Optimal Multilateral Contracts." Economic Theory, 1994, 4, 167187.

Laffont, Jean-Jacques. The Economics of Uncertainty and Information. Cambridge, Mass.: MIT Press, 1989.

Longhofer, Stanley D. "A Note on Absolute Priority Rule Violations, Credit Rationing, and Efficiency." Federal Reserve Bank of Cleveland, unpublished manuscript, October 1994.

Myers, Stewart C. "Determinants of Corporate Borrowing." Journal of Financial Economics, 1977, 5, 147-175. 
Rajan, Raghuram and Andrew Winton. "Covenants and Collateral as Incentives to Monitor." Northwestem University, Working Paper No. 184, July 1994.

Roe, Mark J. "Bankruptcy and Debt: A New Model for Corporate Reorganization." Columbia Law Review, 1983, 83, 527-602.

Rothschild, Michael and Joseph Stiglitz. "Increasing Risk I: A Definition." Journal of Economic Theory, 1970, 2, 225-243. Reprinted in Uncertainty in Economics: Readings and Exercises, Diamond, Peter and Michael Rothschild, eds., San Diego : Academic Press, Inc., 1989.

Stiglitz, Joesph E. and Andrew Weiss. "Credit Rationing in Markets with Imperfect Information." American Economic Review, June 1981, 71(3), 393-410.

Townsend, Robert M. "Optimal Contracts and Competitive Markets with Costly State Verification." Journal of Economic Theory, 1979, 21, 265-293.

White, Michelle J. "Public Policy toward Bankruptcy: Me-First and Other Priority Rules." Bell Journal of Economics, 1980, 11, 550-564.

White, Michelle J. "Bankruptcy Costs and the New Bankruptcy Code." Journal of Finance, 1983, 38, 477-504.

Winton, Andrew. "Costly State Verification and Multiple Investors: The Role of Seniority." Northwestem University, Working Paper, 1992. 